\title{
Extensive Melanotic Neuroectodermal Tumor of Infancy
}

\author{
Assis Filipe Medeiros Albuquerque ${ }^{1} \cdot$ José Ferreira Cunha $^{2}$ Rafael Linard Avelar ${ }^{3,7}$ • \\ Eduardo Juca $^{4} \cdot$ Fabio Wildson Gurgel Costa ${ }^{5}$ Mario Sérgio Macedo ${ }^{6}$
}

Received: 13 October 2015/Accepted: 11 November 2015/Published online: 18 November 2015

(C) Springer Science+Business Media New York 2015

\begin{abstract}
The melanotic neuroectodermal tumor of infancy (MNTI) is a rare childhood neoplasm with an alarming but classical clinical presentation. We present the case of a 2-month-old male infant treated with surgery for an aggressive MNTI on the alveolar process of the maxilla. Radiographic examination showed a diffuse osteolytic radiolucent lesion in the right maxilla, and displacement and dysmorphic changes in the developing primary tooth buds. The patient remained well without evidence of recurrence for 6 months after surgery. We discussed clinicopathological features, management alternatives, and outcome.
\end{abstract}

Rafael Linard Avelar

rafael.linard@hotmail.com

1 Oral and Maxillofacial Surgery Department, Federal University of Ceará, Fortaleza, Brazil

2 Department of Oral and Maxillofacial, Albert Sabin Hospital, Fortaleza, Ceará, Brazil

3 Department of Oral and Maxillofacial, University Center of Christus (Unichristus), Fortaleza, Brazil

4 Department of Neurosurgery, Albert Sabin Hospital of Fortaleza, Fortaleza, Ceará, Brazil

5 Department of Stomatology, Federal University of Ceará, Fortaleza, Brazil

6 Department of Head and Neck Surgery, Albert Sabin Hospital of Fortaleza, Fortaleza, Ceará, Brazil

7 University Center Christus, João Adolfo Gurgel Street, 133, Fortaleza CEP 140120, Brazil
Keywords Melanotic neuroectodermal tumor of infancy $($ MNTI) - Jaw neoplasm $\cdot$ Surgical excision · Tumor recurrence $\cdot$ Intra-oral mass

\section{Case Report}

\section{History}

The patient, a 1-month-old baby boy was brought to the oral and maxillofacial surgery service of the "Hospital Infantil Albert Sabin (HIAS)" with a history of increased volume on the right side of the maxillary region that had started 2 weeks previously. The baby had difficulty with feeding, showed progressive weight loss, and weighed $3 \mathrm{~kg}$ at the time of the exam. The patient's mother reported that two episodes of epistaxis had occurred 3 days before the first consultation.

\section{Clinical Examination}

The physical exam showed a reddish colored exophytic mass with melanotic spots involving the entire right side of the maxilla. The lesion involved the hard palate, nasal cavity, infraorbital margin, and anterior region of the maxilla, displacing the overlying cheek and lip (Fig. 1). It was observed as an alveolar protrusion without evident ulceration, with extensive displacement of teeth.

\section{Radiographic Features}

Computed tomography showed an expansive soft tissue mass measuring $5 \times 7 \times 9 \mathrm{~cm}$ involving the alveoli, with extensive displacement of the tooth germs. The lesion extended in the superior and medial directions, affecting 


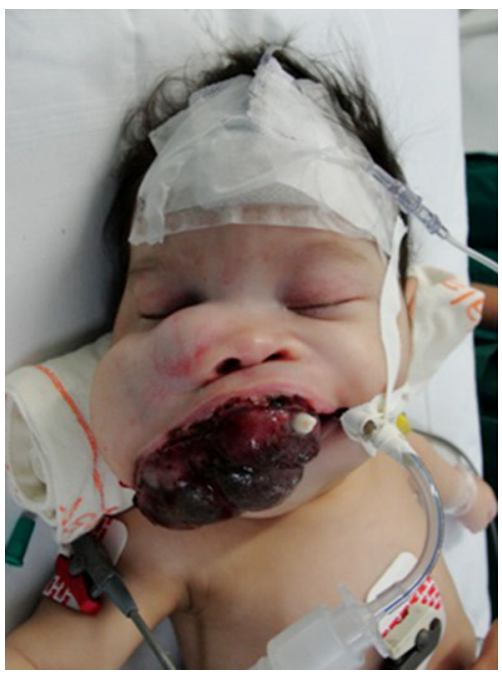

Fig. 1 Extraoral examination showing swelling in the right anterior maxillary region displacing upper lip

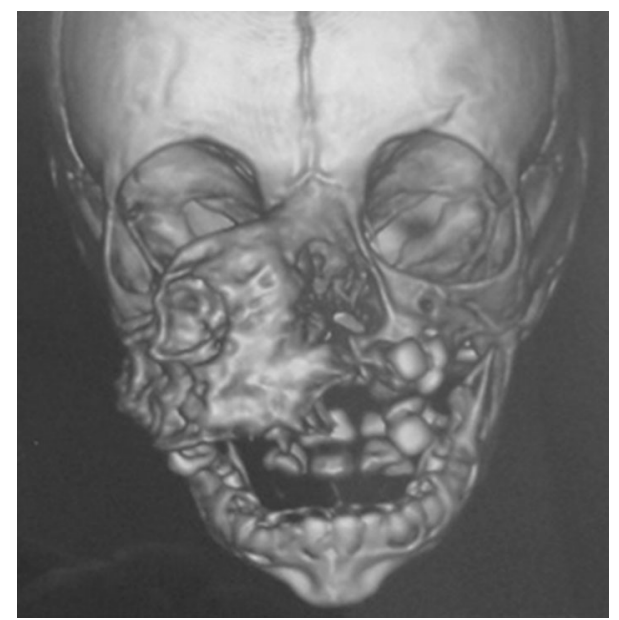

Fig. 2 3D CT demonstrates expansile lesion of the right maxilla with displacement of dental follicles

the ethmoidal cells, and completely obliterating the maxillary sinus on the right side (Fig. 2).

\section{Diagnosis and Management}

After the initial consultation, complementary exams were requested, including vanillylmendelic acid, calcium, and alkaline phosphatase levels, showing that the patient presented with normal serum levels of these factors. There were no changes in the hematological exams.

A biopsy was performed under local anesthesia, resulting in the histopathological diagnosis of MNTI. The histopathological exam stained with HE demonstrated a neoplasm composed of cells with two distinct histological patterns. 1-small, round, and elongated cells with

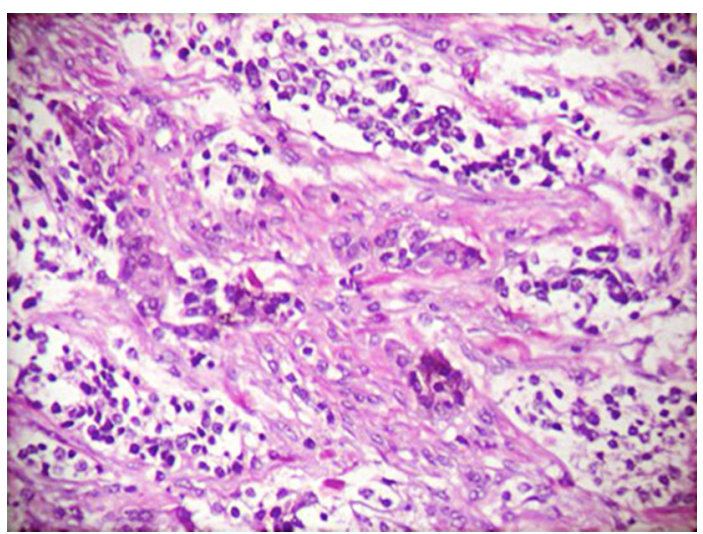

Fig. 3 Photomicrograph showing staining aggregates of small, dark, round neuroblast-like cells amid fibrous stroma (hematoxylin-eosin stain, original magnification $\times 100$ )

hyperchromatic nuclei and scarce cytoplasm. 2-epithelioid cells with broad, round nuclei; regular chromatin arranged in solid blocks, infiltrating the fibrous stroma (Fig. 3); light and amphophilic cytoplasm with brown pigmentation (Fig. 4). Two mitoses were observed in 10 CGA.

Immunohistologic analysis revealed positive staining in both cell lines for neuron-specific enolase. The small neuroblast-like cells expressed synaptophysin (Fig. 5). The melanin-containing epithelioid cells showed a high immunoreactivity for HMB-45 (Fig. 6).

Due to the large extent of the lesion, the patient was subjected to a tracheostomy, and fed via nasogastric tube. An incisional biopsy was performed, and the patient underwent complete enucleation of the lesion, with a Weber Ferguson facial incision. Then, a complete maxillectomy of the affected right side was performed, also removing the orbital floor and medial orbital wall. As a result of the large defect observed, hemicoronal access to

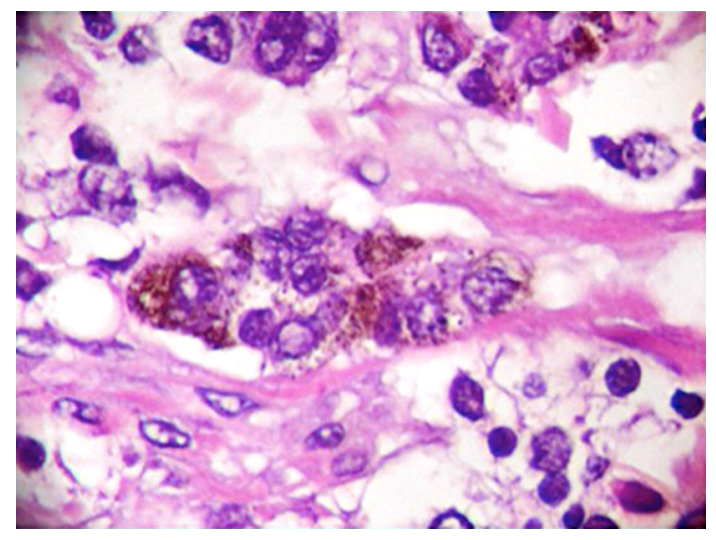

Fig. 4 Photomicrograph showing islands of relatively larger melanin-containing cells amid fibrous stroma (hematoxylin-eosin stain, original magnification $\times 400$ ) 


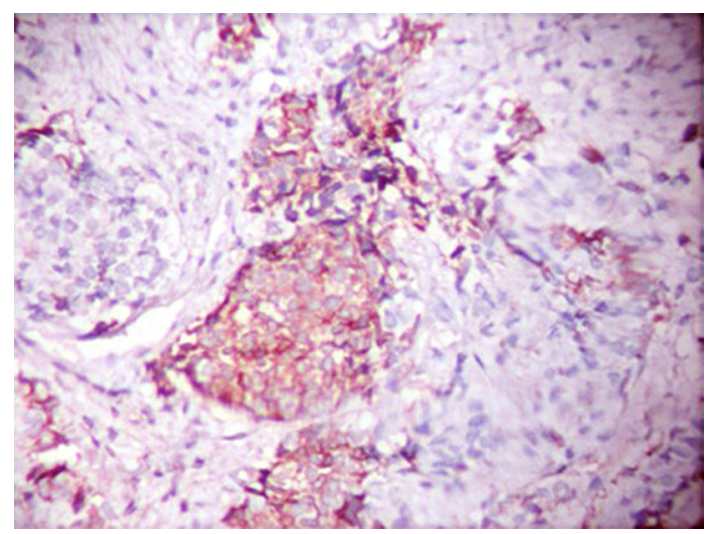

Fig. 5 Synaptophysin was expressed by the small round neuroblastlike cells (magnification $\times 100$ )

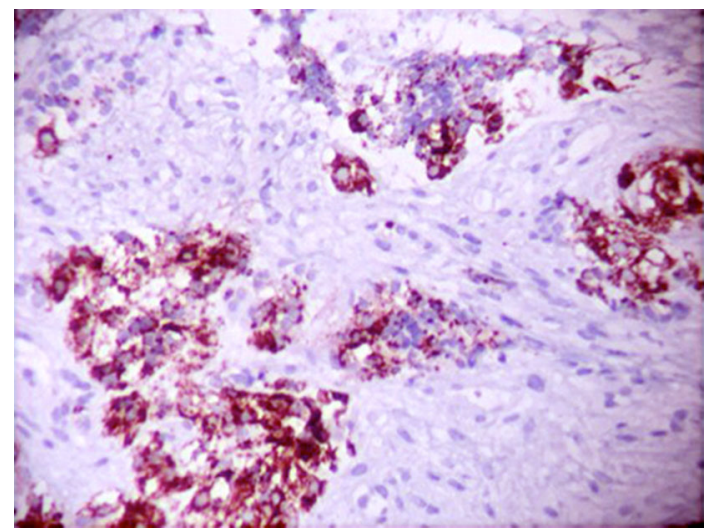

Fig. 6 Clusters of large epithelial-like cells were positive for HMB45 (magnification $\times 200$ )

remove a cranial cap graft was performed. Later, the orbital floor and medial orbital wall were reconstructed, and closed the area by using the buccal fat pad, thereby avoiding fistulas in the palatal region. Then the tracheostomy and nasogastric tube were removed 20 days after the surgical procedure.

The post-operative period proceeded without intercurrences, and up to now, we have followed-up the patient for 6 months post-operatively, without clinical signs of recurrence.

\section{Discussion}

Because of their low occurrence, with approximately 360 cases described in the medical literature [1-3], this lesion has raised intense controversy with regard to its origin and pathophysiology. This tumor usually appears in children under the age of 1 year [4, 5], with an approximately equal distribution between the sexes $[4,6]$. Normally it arises in the head and neck region, mainly affecting the maxilla, although other sites, such as the brain, epididymis [7], mediastinum, femur and ovary $[8,9]$ may be affected.

Clinically, the tumor appears irregularly pigmented with coloring varying between brown and blue; it may contain extremely displaced primary teeth. MNTI is a fast-growing, non-ulcerated lesion with a lobular shaped increase in volume that mainly occurs in the craniofacial region (maxilla, mandible, cranium, and brain). Pigmentation may or may not be seen in the overlying soft tissue. This condition is generally found in patients under the age of 1 year, usually without predilection for sex $[1,8,10,11]$, although in some review studies of cases described in the literature, we observed a slight predilection for the male sex $[1,8,12-14]$. In spite of being locally invasive, these tumors are generally described as being benign. Radiographs have frequently shown a destructive radiolucency, presenting poor demarcation of the subjacent bone, perhaps with a smooth appearance of calcifications along the vessels irradiating from the center of the tumor [8].

Studies have used conventional radiographs, computed tomography (CT) and magnetic resonance imaging exams to evaluate the content and extent of MNTIs. This lesion has a well-circumscribed radiographic appearance within the bone (in the majority of cases) and presents with radiolucency, although aggressive examples with poor bone delimitation may be seen, as was shown in the present case $[3,15]$. The bone involved was destroyed, but we observed no well defined limits, thus suggesting a malignant process [3, 16], that could be multilocular [17]. CT with intravenous contrast is frequently used to delineate the margins of bone involvement. Furthermore, the magnetic resonance image with gadolinium contrast could be used to evaluate the extent of the bone lesion $[3,16]$.

Since the first description by Krompecher [2], who called the lesion congenital melanocarcinoma, studies have proposed various theories for the origin of this tumor [10]. Some researchers believed that it originated from the retinal anlage, whereas others believed it to be of odontogenic origin $[10,18]$. One of the theories proposed arises from the fact that the tumor is reminiscent of the initial stages of retina development (retinal anlage tumor) [19, 20]. However, the retinal anlage theory was contested because the retina becomes well organized in the embryonic stage at $7 \mathrm{~mm}$, when the maxilla is only beginning to form [1].

Investigators believed it would be unlikely that the highly differentiated retinal tissue could be compressed outside of the less differentiated tissue of the maxilla. Furthermore, no tissue similar to that of the sclera was identified, and the eyes of these patients are generally normal. Therefore, the majority of authors believe that the tumor originates from neural crest cells [1, 3, 5, 8-10].

Support for this neuroectodermal origin stems from the secretion of vanillylmandelic acid that may be increased in 
these patients, or other catecholamines by neoplastic cells, a finding characteristic of other tumors originating from the neural crest, such as pheochromocytoma, neuroblastoma and ganglioneuroblastoma [21]. In patients with elevated levels, the vanillylmandelic acid levels generally return to normal after the tumor is excised, which provided more support for this theory [15]. Additional support for the neuroectodermal derivation is the expression of melanotransferrin in MNTI $[9,22]$.

Microscopically, MNTIs are biphasic tumors composed of small-cell and large-cell components, arranged in nestlike or alveolar formations embedded within a well-vascularized fibrous stroma. The nests of small cells are usually surrounded by large cells forming gland-like structures and containing various amounts of melanin granules in their cytoplasm. The immunohistochemical profile of MNTI is similar in all reported studies. The main characteristic cells are: small cells of neural origin, confirmed by NSE, synaptophysin, and chromogranin positivity; large cells of ectodermal origin, confirmed by EMA, CK, and HMB-45 positivity [10].

The treatment of choice for the neuroectodermal tumor of infancy (MNTI) is surgical excision that is usually curative [23]. This treatment may be accompanied by a complete or partial maxillectomy, depending on the extent of the tumor, and the Weber Ferguson access or facial degloving may be used, when necessary [3]. Teeth and soft tissues adjacent to the lesion must be removed, to diminish the chance of recurrence. Some authors argue that a margin of $5 \mathrm{~mm}$ of healthy tissue must be included in the surgically removed part [11, 23].

Unfortunately, the biologic behavior of the neoplasm cannot be predicted by macroscopic or histological characteristics, therefore it demands strict post-operative follow-up $[14,22]$. Reports have indicated a local recurrence of up to $45 \%$ after conservative excision [14]. Some authors have demonstrated a significant reduction in the neuroblastic-like component with the use of chemotherapy $[14,24]$.

The neuroectodermal melanocytic tumor of infancy is a benign neoplasm, but in $7 \%$ of the cases reported, metastatic appearances were located in various anatomic points of the human body, generally under the definition of recurrent disease $[9,24,25]$. Clinical and histological risk factors and the interval between initial treatment and development of metastatic disease were not characterized in the literature [25].

The neuroectodermal melanocytic tumor of infancy is a fast growing lesion, initially presenting in the first year of life, requiring diagnosis by means of incisional biopsy. In extreme cases, when the histopathological exam does not confirm the suspicion, immunohistochemical analysis must be performed.
Surgical resection must preserve the function of vital structures and organs. Recurrence generally occurs in the first year after surgery. Children under the age of 3 years must be closely followed-up with the purpose of evaluating a possible recurrence.

\section{Compliance with Ethical Standards}

Conflict of interest None.

\section{References}

1. Rustagi A, Roychoudhury A, Karak AK. Melanotic neuroectodermal tumor of infancy of the maxilla: a case report with review of literature. J Oral Maxillofac Surg. 2011;69(4):1120-4.

2. Krompecher E. Zur histogenese und morphologie der adamantinome und sonstiger kiefergeschwülste. Beitr Path Anat. 1918;64:32.

3. Selim H, Shaheen S, Barakat K, Selim AA. Melanotic neuroectodermal tumor of infancy: review of literature and case report. J Pediatr Surg. 2008;43(6):E25-9.

4. Hoshina Y, Hamamoto Y, Suzuki I, Nakajima T, Ida-Yonemochi $\mathrm{H}$, Saku T. Melanotic neuroectodermal tumor of infancy in the mandible: report of a case. Oral Surg Oral Med Oral Pathol Oral Radiol Endod. 2000;89(5):594-9.

5. de Souza PE, Merly F, Maia DM, Castro WH, Gomez RS. Cell cycle-associated proteins in melanotic neuroectodermal tumor of infancy. Oral Surg Oral Med Oral Pathol Oral Radiol Endod. 1999;88(4):466-8.

6. Koral K, Derinkuyu B, Timmons C, Schwartz-Dabney CL, Swift D. Melanotic neuroectodermal tumor of infancy: report of one calvarial lesion with $\mathrm{T} 1$ shortening and one maxillary lesion. Clin Imaging. 2010;34(5):382-4.

7. Borello ED, Gorlin RJ. Melanotic neuroectodermal tumor of infancy-a neoplasm of neural crese origin. Report of a case associated with high urinary excretion of vanilmandelic acid. Cancer. 1966;19(2):196-206.

8. Kruse-Losler B, Gaertner C, Burger H, Seper L, Joos U, Kleinheinz J. Melanotic neuroectodermal tumor of infancy: systematic review of the literature and presentation of a case. Oral Surg Oral Med Oral Pathol Oral Radiol Endod. 2006;102(2):204-16.

9. de Oliveira MG, Thompson LD, Chaves AC, Rados PV, da Silva Lauxen I, Filho MS. Management of melanotic neuroectodermal tumor of infancy. Ann Diagn Pathol. 2004;8(4):207-12.

10. Manojlovic S, Virag M, Luksic I, Muller D. Melanotic neuroectodermal tumour of infancy: report of two cases and review of the literature. J Craniomaxillofac Surg. 2012;40(4):e103-7.

11. Hupp JR, Topazian RG, Krutchkoff DJ. The melanotic neuroectodermal tumor of infancy. Report of two cases and review of the literature. International. J Oral Surg. 1981;10(6):432-46.

12. Johnson RE, Scheithauer BW, Dahlin DC. Melanotic neuroectodermal tumor of infancy. A review of seven cases. Cancer. 1983;52(4):661-6.

13. Mirich DR, Blaser SI, Harwood-Nash DC, Armstrong DC, Becker LE, Posnick JC. Melanotic neuroectodermal tumor of infancy: clinical, radiologic, and pathologic findings in five cases. AJNR Am J Neuroradiol. 1991;12(4):689-97.

14. Pettinato G, Manivel JC, d'Amore ES, Jaszcz W, Gorlin RJ. Melanotic neuroectodermal tumor of infancy. A reexamination of a histogenetic problem based on immunohistochemical, flow cytometric, and ultrastructural study of 10 cases. Am J Surg Pathol. 1991;15(3):233-45. 
15. Fowler DJ, Chisholm J, Roebuck D, Newman L, Malone M, Sebire NJ. Melanotic neuroectodermal tumor of infancy: clinical, radiological, and pathological features. Fetal Pediatr Pathol. 2006;25(2):59-72.

16. Suzuki C, Maeda M, Matsushima N, Takamura M, Matsubara T, Taki W, et al. Melanotic neuroectodermal tumor of infancy in the skull: CT and MRI features. J Neuroradiol. 2007;34(3):212-3.

17. Steinberg B, Shuler C, Wilson S. Melanotic neuroectodermal tumor of infancy: evidence for multicentricity. Oral Surg Oral Med Oral Pathol. 1988;66(6):666-9.

18. Dooling EC, Chi JG, Gilles FH. Melanotic neuroectodermal tumor of infancy: its histological similarities to fetal pineal gland. Cancer. 1977;39(4):1535-41.

19. Allen MS Jr, Harrison W, Jahrsdoerfer RA. "Retinal anlage" tumors. Melanotic progonoma, melanotic adamantinoma, pigmented epulis, melanotic neuroectodermal tumor of infancy, benign melanotic tumor of infancy. Am $\mathrm{J}$ Clin Pathol. 1969;51(3):309-14.

20. Lamping KA, Albert DM, Lack E, Dickersin GR, Chapman PH, Walton DS. Melanotic neuroectodermal tumor of infancy (retinal anlage tumor). Ophthalmology. 1985;92(1):143-9.
21. Kim YG, Oh JH, Lee SC, Ryu DM. Melanotic neuroectodermal tumor of infancy. J Oral Maxillofac Surg. 1996;54(4):517-20.

22. Kapadia SB, Frisman DM, Hitchcock CL, Ellis GL, Popek EJ. Melanotic neuroectodermal tumor of infancy. Clinicopathological, immunohistochemical, and flow cytometric study. Am J Surg Pathol. 1993;17(6):566-73.

23. Dashti SR, Cohen ML, Cohen AR. Role of radical surgery for intracranial melanotic neuroectodermal tumor of infancy: case report. Neurosurgery. 1999;45(1):175-8.

24. Mello RJ, Vidal AK, Fittipaldi HM Jr, Montenegro LT, Calheiros LM, Rocha GI. Melanotic neuroectodermal tumor of infancy: clinicopathologic study of a case, with emphasis on the chemotherapeutic effects. Int J Surg Pathol. 2000;8(3):247-51.

25. Magliocca KR, Pfeifle RM, Bhattacharyya I, Cohen DM. Melanotic neuroectodermal tumor of infancy. Pediatr Dermatol. 2012;29(5):633-6. 